\title{
Sustainable and harmonious development of the personality in the context of implementation of the concept of pedagogical facilitation
}

\author{
Tatyana Zagorulya* \\ Ural State Economic University, 8 Marta Str., 62, 620144 Yekaterinburg, Russia
}

\begin{abstract}
In the article, the author presents the results of research on sustainable and harmonious development of personality in the context of implementation of the concept of pedagogical facilitation. The author's concept of pedagogical facilitation, based on K. Rogers' theory, has been implemented over years at the Ural State University of Economics. In this article, the author considers her own experience of applying the methods of goal setting, which contribute to the sustainable and harmonious development of the personality. In the context of implementation of the concept of pedagogical facilitation, self-actualization of the individual is carried out, the life scenario is developed, in which priority goals, and ways of achieving them are identified. The obtained result of the study confirms that personal, professional and social goal setting is an important factor of sustainable and harmonious development of the personality in an unstable and constantly changing environment.
\end{abstract}

\section{Introduction}

The concept of sustainable development includes a wide range of topical research issues in economics, ecology, and education. These issues are addressed at international, state and regional levels. The concept of sustainable development includes the aspect of the harmonious development of the personality. In the XXI century sustainable and harmonious development of the personality is an important task in modern education. Harmonious development of the personality presupposes holistic, all-round development of the personality, including self-realization, realization of personal potential, abilities and skills. In the context of implementation of the concept of pedagogical facilitation, it is possible not only to create a success situation for each student who masters general cultural and professional competencies in the educational process, but also a favorable situation for the harmonious development of the personality. It should be noted that the author's concept of pedagogical facilitation, based on the ideas of $\mathrm{K}$. Rogers, is being currently implemented at the Ural State University of Economics (Ekaterinburg). The results of years long research are presented in the scientific publications of the author $[1,2]$. The ideas and principles of pedagogical facilitation considered by domestic $[3,4]$ and foreign authors $[5,6]$ are relevant in the context of sustainable development concept.

\footnotetext{
*Corresponding author: tatbor.07@mail.ru
} 


\section{Materials and methods}

The purpose of research is to identify the significance of the conditions implementing the concept of pedagogical facilitation for sustainable and harmonious development of personality.

\section{Research objectives:}

- continuing experimental work to identify the significance of the conditions for implementing the concept of pedagogical facilitation for sustainable and harmonious development of the personality;

- continuing the creation of facilitating learning conditions in the classroom, contributing to sustainable and harmonious development of the personality;

- applying the methods of goal and objectives setting, which contribute to sustainable and harmonious development of personality;

- analyzing the obtained results of applying the above mentioned methods.

Research methods: theoretical - analysis, synthesis, comparison, generalization; empirical - document analysis; pedagogical observation; self-assessment; experimental work; content analysis.

\section{Results and discussion}

In the course of research, the authors concluded that in the context of implementing the concept of pedagogical facilitation, sustainable and harmonious development of the personality is effective and successful. The principles of facilitating learning (according to K. Rogers) [7, 8], such as trust, authenticity, unconditional acceptance, the idea of freedom in learning make the basis on which the system of subject-subject relationship between teacher and student, parity relations are built when the students can reveal their personal potential and achieve the set goal.

In our opinion, the concept of "personality" is important for our research topic. When considering the concept of "personality", we should note that there is no unambiguous definition in the scientific literature. Many definitions of "personality" are explained by different scientific approaches to its study. An interesting research was conducted by A.V. Tolstykh, who established (from a linguistic point of view) the relationship of the Latin "persona" with the modern "personality" (English), "personalite" (French), "personlichkeit" (German). According to Tolstykh, there is a convergence of one of the meanings of the Latin "persona" ("mask", "role" performed by an actor) with the so-called "social roles", which are considered by researchers as an essential definition of the psychological structure of a personality [9].

Psychologist A. G. Asmolov presented three hypostases (from the Greek Hypostasis - the essence, the basis) of a person, revealing his/her essence as a person [10]:

- a person as a multidimensional being, manifesting simultaneously as a participant in the historical and evolutionary process; a carrier of social roles and a subject choosing an individual life path;

- a person as a biased dialogical poly-activity being, whose essence is generated, transformed and defended in existence - in the world, in other people, in himself/herself;

- a person as a subject of free responsible purposeful behavior, acting as a value in the perception of other people, including himself/herself, and having a relatively autonomous stable integral system of diverse individual features

As part of the study of the educational discipline "Fundamentals of Management" Locke's goal-setting theory is considered, which is relevant and consonant with the concept of sustainable development and harmonious personal development. The behavioral model of a person, according to E. Locke, is formed and determined by the goals that a person sets for 
himself/herself. Goal setting is an important and complex process that requires human effort, awareness and responsibility. Setting goals includes the following stages: a person's awareness and assessment of events taking place in his/her environment, taking into account the emotional state; defining the goal that sets the direction and intensity of actions, performance of work; achieving a certain result; satisfaction (satisfaction with the result).

It should be noted that going through these stages returns a person to the first stage. This is because a person finds himself in various production / life situations when they need to set goals. E. Locke introduces the concepts of "level of performance" and "quality of performance". Thus, the level of work performance is determined by the complexity, specificity, acceptability, commitment. The quality of performance depends both on the goals set by the employee and on organizational factors and human abilities. In this case, the named factors influence the goals, affecting motivation, performance and results [11]. In our opinion, focusing the attention of students on motivation and goal setting both in the professional sphere and in personal life is necessary and required. Carrying out facilitation classes in the discipline "Fundamentals of Management", we teach students to form both short-term and long-term goals. For this, the author of the article uses various techniques that help students develop skills in planning their present and future periods of life.

In the context of the implementation of the concept of pedagogical facilitation, we applied the methodology of a personality's life scenario. According to E. Berne: "A scenario is a constantly unfolding life plan, which is formed in early childhood and mainly under the influence of parents. This psychological impulse with great force pushes a person forward, towards his fate, and very often regardless of his/her resistance or free choice "[12]. Thanks to the ability of setting goals and going through goal-setting stages, a person determines his/her fate, predetermines the outcome of events in personal, professional and social life. The named methodology awakens and encourages students to think about the meaning of life, about what role everyone can play in it, how they can self-actualize and reveal their potential.

L.D. Stolyarenko [13] bases this methodology on the developing task «Life goals». It includes questions and presenting your self-image (self-perception) in the past (childhood drawings and memories), in the present and in the future (at which step of the life-ladder you were 6 years ago, you are at present and you will be in 5 years).

Full-time 18-22 -year old students specializing in Management performed the task, 84 people in total. After analyzing the answers according on the criterion of self-realization in personal, professional and social spheres, we concluded that students have goals related to getting higher education $-85 \%$; good job - $80 \%$; having a strong and friendly family $-40 \%$; having their own business and earning money - $24 \%$; living independently of their parents $-6 \%$; learning a foreign language $-8 \%$; providing assistance and support to parents - $5 \%$; doing sports, having healthy lifestyle $-2 \%$; being engaged in creative activities (art, cinema) - $2 \%$. It should be noted that setting goals for students is a priority in the personal sphere, although social and professional orientation and goal - setting are expressed.

For example, the received answers were that students are ready to help people and to be volunteers - 3\%; make people happy - 3\%; support animals - 3\%; be famous and popular persons in the community - $2 \%$. We also noted the high level of self-esteem and criticality demonstrated by students when answering the question about what prevents them from achieving their goals. Most often, the reasons were as follows: laziness, lack of sufficient financial resources to achieve the set goal, no support from loved ones, limited time, etc. Applying the methodology "Personal Life Scenario" proves its effectiveness in goal setting in personal, professional and social spheres. Everyone works out the life scenario taking into account the past, present and future, retaining the emotional element (which is also discussed in E. Locke's goal setting theory) through the memories of significant events that took place in each person's childhood and were reflected in the life scenario. 
Along with the "Personal Life Scenario", the author of the article uses the methodology "Declaration of Goals" in facilitation classes [14]. The elements of this technique are as follows: promise, word price, curator, publicity. Students complete the assignment by developing their "Declaration of Goals", where the first element "promise" is the main goal that is meaningful to them at the moment. For example, student declarations contained the following promises: "pass the exams with excellent grades", "take driving courses and get a driving license", "regularly attend the fitness center". The element "price of a word" means the personal degree of responsibility for the "promise". The element "price of a word" contains a motivator and a demotivator. The positive motivation is "if the promise is fulfilled and the goal is achieved I will be rewarded." The negative motivation is "if I do not fulfill my promise and I do not achieve my goal, I will be reprimanded"

Further, having identified the motivator / demotivator in the "price of the word," the students found a "curator," a kind of "persona grata," a person they trust. The "curator" confirmed that "promise" and "price of the word" are important to the drawer of the declaration. As a "curator", as a rule, students chose their close friends. The next stage in implementing the "Declaration of Goals" is publicity, when the goal is published in a social network, blog, on the website of the declaration drawer. Using observation and survey methods, we received feedback from the students who drew up the "Declarations of Goals". The received feedback was as follows: "the experience of drawing up the declaration was interesting and useful", "this technique allows not only setting a goal, but also helps to develop self-discipline", "the declaration of goals helps to control oneself, one's progress towards the set goal "," publicity makes one be more responsible in achieving the goal, because this process is watched by others, not just yourself. " Receiving positive feedback from students enables the researchers to assume that sustainable and harmonious development of the personality is possible in the context of implementation of the concept of pedagogical facilitation by using relevant techniques focused on revealing the individual's potential through goal-setting and identifying objectives

\section{Conclusions}

Having presented the result of our research, we can conclude that sustainable and harmonious development of a personality is possible in the context of implementation of the concept of pedagogical facilitation.

The research objectives were completed: experimental work continued on implementing the author's concept of pedagogical facilitation in the context of sustainable and harmonious development of the personality (in this article, the author presents her own work experience).

It should be noted that in modern society every person performs many social roles, while independently choosing the vector of personal, social and professional development. Every person develops his/her life scenario, sets goals, and chooses the ways of achieving these goals. The personality has an integral system of individual features and characteristics, but harmonious development requires special conditions, which are the conditions for implementing the concept of pedagogical facilitation.

Positive feedback from students confirms the assumption that pedagogical facilitation creates a success situation for each student, realizes the idea of freedom in learning. E. Locke's theory of goal setting is studied as part of the academic discipline "Fundamentals of Management", actual methods of goal setting and objectives identification are applied ("Personal Life Scenario", "Declaration of Goals"), which are focused on the personality's self-actualization, self-realization, personal potential fulfilment. 


\section{References}

1. T.B. Zagorulya, Scientific journal "Scientific opinion", 3 (2020)

2. T.B. Zagorulya, Online learning using distance technologies in the context of the implementation of the concept of pedagogical facilitation, Advances in Social Science, Education and Humanities Research, volume 437 International Scientific Conference "Digitalization of Education: History, Trends and Prospects", WoS. Scopus (DETP 2020)

3. M.N. Dudin, Higher School Didactics: From Traditions to Innovations (2015)

4. R.V. Ovcharova, Psychological Facilitation of the Work of a School Teacher (2007)

5. B. Rienties, N. Brouwer, S. Lygo-Baker, Teaching and Teacher Education, 29 (2013)

6. A.Y.N. Cheng, E. Szeto, Teaching and Teacher Education, 58 (2016)

7. C. R. Rogers, Freedom to learn for the 80s, Columbus (1982)

8. C. R. Rogers, Client-Centered therapy: its current practice implications a. theory, London (1991)

9. A.V. Tolstykh, Experience of Concrete Historical Psychology of Personality (2000)

10. A.G. Asmolov, Psychology of Personality (1990)

11. A.Yu. Ryabtsev, T.B. Zagorulya, Management: economic aspects of management (2017)

12. E. Bern, Games People Play. People who play games (1996)

13. L. D. Stolyarenko, Fundamentals of Psychology (1997)

14. T.B. Zagorulya, Facilitation of a manager in professional activities (2019) 